BMC

Genomics

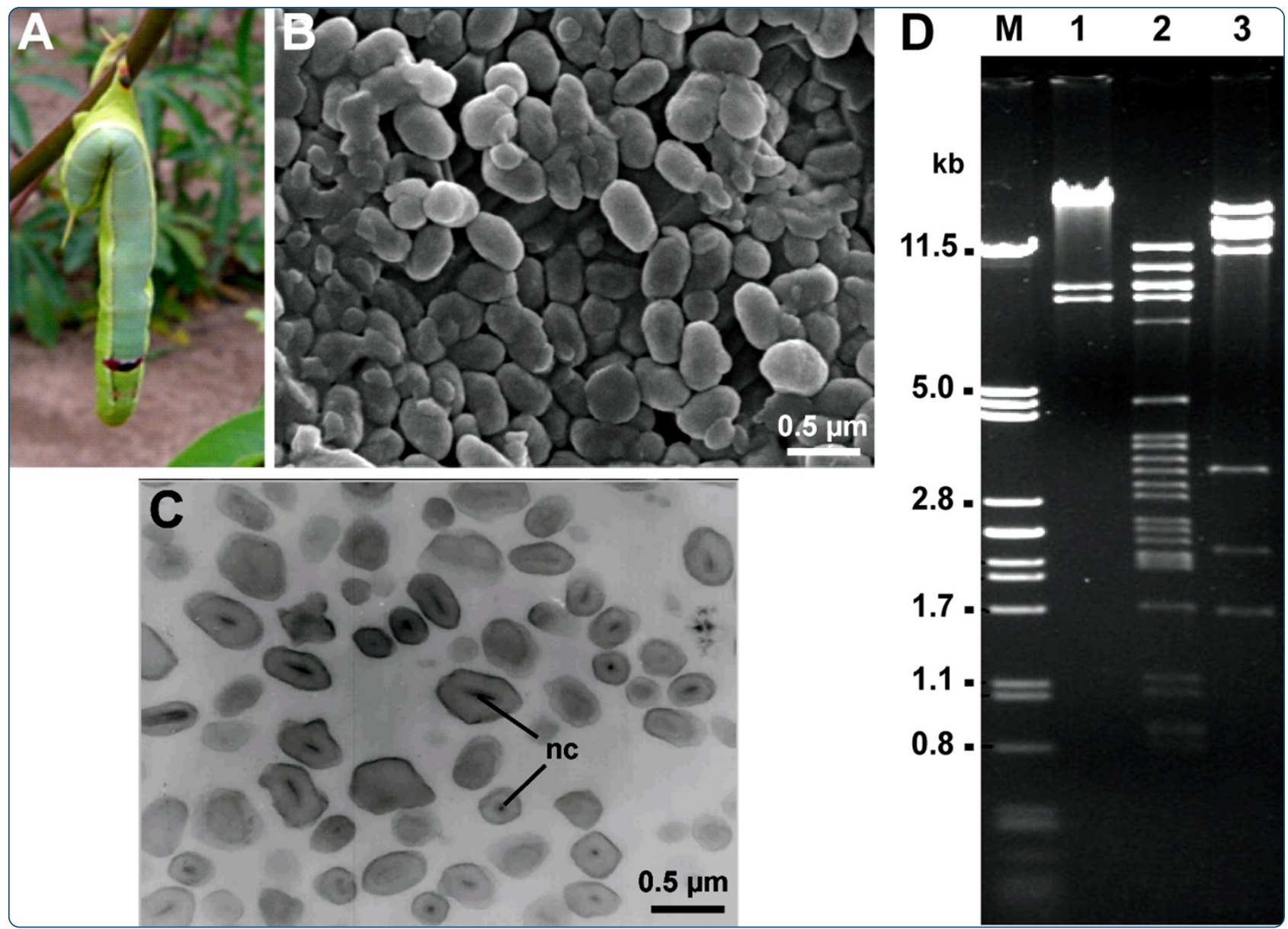

Genome sequence of Erinnyis ello granulovirus (ErelGV), a natural cassava hornworm pesticide and the first sequenced sphingid-infecting betabaculovirus

Ardisson-Araújo et al.

C Biomed Central 


\title{
Genome sequence of Erinnyis ello granulovirus (ErelGV), a natural cassava hornworm pesticide and the first sequenced sphingid-infecting betabaculovirus
}

Daniel Mendes Pereira Ardisson-Araújo ${ }^{1}$, Fernando Lucas de Melo ${ }^{1}$, Miguel de Souza Andrade', William Sihler², Sonia Nair Báo ${ }^{1}$, Bergmann Morais Ribeiro ${ }^{1 *}$ and Marlinda Lobo de Souza ${ }^{2}$

\begin{abstract}
Background: Cassava (Manihot esculenta) is the basic source for dietary energy of 500 million people in the world. In Brazil, Erinnyis ello ello (Lepidoptera: Sphingidae) is a major pest of cassava crops and a bottleneck for its production. In the 1980s, a naturally occurring baculovirus was isolated from E. ello larva and successfully applied as a bio-pesticide in the field. Here, we described the structure, the complete genome sequence, and the phylogenetic relationships of the first sphingid-infecting betabaculovirus.

Results: The baculovirus isolated from the cassava hornworm cadavers is a betabaculovirus designated Erinnyis ello granulovirus (ErelGV). The 102,759 bp long genome has a $\mathrm{G}+\mathrm{C}$ content of $38.7 \%$. We found 130 putative ORFs coding for polypeptides of at least 50 amino acid residues. Only eight genes were found to be unique. ErelGV is closely related to ChocGV and PiraGV isolates. We did not find typical homologous regions and cathepsin and chitinase homologous genes are lacked. The presence of he65 and p43 homologous genes suggests horizontal gene transfer from Alphabaculovirus. Moreover, we found a nucleotide metabolism-related gene and two genes that could be acquired probably from Densovirus.

Conclusions: The ErelGV represents a new virus species from the genus Betabaculovirus and is the closest relative of ChocGV. It contains a dUTPase-like, a he65-like, p43-like genes, which are also found in several other alpha- and betabaculovirus genomes, and two Densovirus-related genes. Importantly, recombination events between insect viruses from unrelated families and genera might drive baculovirus genomic evolution.
\end{abstract}

Keywords: Biological control, Cassava hornworm, Baculovirus, Sphingidae, Horizontal gene transfer, Betabaculovirus evolution

\section{Background}

Cassava (Manihot esculenta) is the basic source for dietary energy of 500 million people in tropical and subtropical areas of Africa, Asia, and Latin America [1]. In Brazil, the hornworm Erinnyis ello ello (Lepidoptera: Sphingidae) is one of the most important pests [2] occurring throughout the year and greatly impacting cassava production [3,4]. This pest has been observed in 35 plant species, especially

\footnotetext{
*Correspondence: bergmann@unb.br

'Cell Biology Department, Laboratory of Baculovirus, University of Brasilia, 70910-900 Brasília, DF, Brazil

Full list of author information is available at the end of the article
}

in the Euphorbiaceae family $[5,6]$. In large infestations, the cassava pest may reduce by $50 \%$ the roots yield. In the 1980s, a naturally occurring baculovirus was isolated from this pest and applied as a bio-pesticide in Brazil [5]. The biological control program has proven to be safe and economical $[5,6]$. However, genomic and structural information about this virus is lacking.

The Baculoviridae is a family of insect viruses with circular double-stranded genomic DNA [7-9] that have been successfully applied for the control of agricultural and forest pests [10]. So far, Alpha and Betabaculovirus are the most studied baculovirus genera; both infect Lepidoptera 
[7]. The infection is initiated when larvae feed on foliage contaminated with orally infectious occlusion bodies (OBs) [11] that release occlusion derived-virions (ODVs) in the midgut [12]. Early after primary midgut epithelial cell infection, budded virions (BV) are produced and cause systemic infection. Infection symptoms include cuticle discoloration, movement loss, and incapability for feeding $[13,14]$.

Few full-length betabaculovius genome sequences are available compared to those from Alphabaculovirus and none of them was isolated from sphingid host. In this context, identification and sequencing of virus species from different lepidopteran families will provide a wider empirical database to help understand baculovirus evolution $[15,16]$. Here, we presented the morphological characterization, the complete genome sequence, and the phylogenetic analyses of the natural cassava hornworm pesticide, the first completely sequenced betabaculovirus isolated from a sphingid host.

\section{Results and discussion}

\section{Virus characterization and genome features}

A naturally occurring baculovirus was isolated from dead cassava hornworm (E. ello ello) caterpillars in crops from the South of Brazil in 1986. As shown in Figure 1A, the larvae is usually found hanged in cassava apical leaves, which is a characteristic symptom of the baculovirus infections [17]. Neither cuticle melanization nor post-mortem melting phenotypes were observed among the caterpillar cadavers, an attribute which probably facilitated virus collection and use for pesticide production as previously observed in another baculovirus (Anticarsia gemmatalis multiple nucleopolyhedrovirus - AgMNPV) [10]. Ultrastructural analyses revealed a granular $\mathrm{OB}$ with irregular form and size (Figure 1B) containing single rod-shaped nucleocapsid (Figure 1C). Both of these structural features, i.e. granular form and nucleocapsid shape, are typical of viruses from the genus Betabaculovirus $[8,18]$ and thus, we named it Erinnyis ello granulovirus (ErelGV) isolate Br-S86 (Brazil/ South/1986). Two other cassava hornworm-isolated granuloviruses were previously reported, one isolated in Colombia [19] and another from an undisclosed geographical source [20]. Restriction endonuclease profile analyses (Figure 1D) suggest that the Brazilian and the Colombian viruses (previously published in [19]) are either variants of the same species or are distinct species infecting the same host. However, the absence of sequence data from the latter prevents establishment of any phylogenetic relationship.

We sequenced the genome of ErelGV, the first completely sequenced sphingid host-isolated betabaculovirus (Genbank accession number KJ406702). The genome is 102,759 bp long with a $\mathrm{G}+\mathrm{C}$ content of $38.7 \%$ (Table 1 ). We found 130 putative genes coding for polypeptides of at least 50 amino acid residues. Additional file 1: Table S1 summarizes the ErelGV genes and compares each predicted protein sequence with its orthologs in other baculoviruses. Eight of these were shown to be unique (ErelOrf-11, ErelOrf-15, ErelOrf-27, ErelOrf-53, ErelOrf-59, ErelOrf-70, ErelOrf-90, ErelOrf-102), and all of them are peptides with no significant similarity to any other sequence in GenBank. All 37 Baculoviridae core genes were found and no typical homologous regions (hrs)

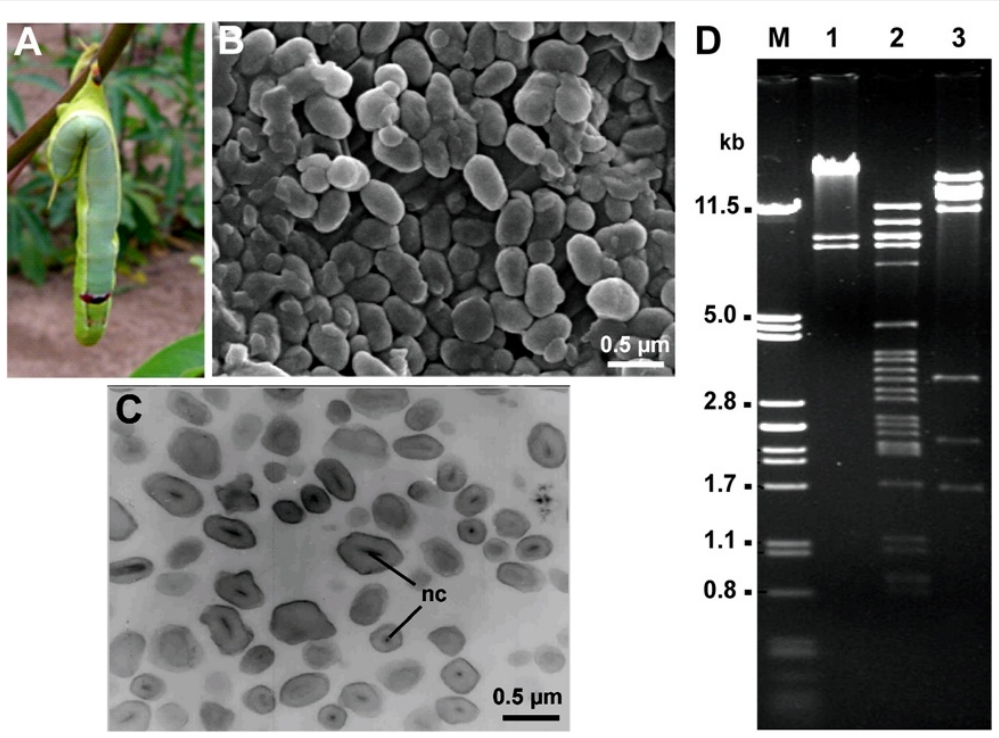

Figure 1 Erinnyis ello granulovirus (ErelGV) infection and virus characterization. (A) Cassava hornworm cadaver found hanging in the field due to terminal baculovirus infection (Source: José Osmar Lorenzi). (B) Scanning and (C) transmission electron micrographs reveal granular occlusion bodies containing singly embedded rod-shaped nucleocapsid (nc) (scale bars $=0.5 \mu \mathrm{m}$ ). (C) Restriction enzyme profile of Brazilian isolate genomic DNA. Agarose gel electrophoresis-resolved DNA fragments digested with Hindlll (lane 1), EcoRI (lane 2), BamHI (lane 3). 
Table 1 All species from the genus Betabaculovirus completely sequenced to date

\begin{tabular}{|c|c|c|c|c|c|}
\hline Virus species & Host Family & Size (bp) & ORFs & Accession & Refs. \\
\hline Adoxophyes orana granulovirus & Tortricidae & 99,657 & 119 & AF547984 & [23] \\
\hline Agrotis segetum granulovirus Xinjiang & Noctuidae & 131,680 & 132 & AY522332 & [24] \\
\hline Agrotis segetum granulovirus L1 & Noctuidae & 131,442 & 149 & KC994902 & {$[24]$} \\
\hline Choristoneura occidentalis granulovirus & Tortricidae & 104,710 & 116 & DQ333351 & [21] \\
\hline Clostera anachoreta granulovirus & Notodontidae & 101,487 & 123 & HQ116624 & {$[25]$} \\
\hline Clostera anastomosis L. granulovirus & Notodontidae & 101,818 & 123 & KC179784 & $u / d$ \\
\hline Cryptophlebia leucotreta granulovirus & Tortricidae & 110,907 & 129 & AY229987 & {$[26]$} \\
\hline Cydia pomonella granulovirus & Tortricidae & 123,500 & 143 & U53466 & {$[27]$} \\
\hline Epinotia aporema granulovirus & Tortricidae & 119,092 & 132 & JN408834 & {$[28]$} \\
\hline Erinnyis ello granulovirus & Sphingidae & 102,759 & 135 & KJ406702 & - \\
\hline Helicoverpa armigera granulovirus & Noctuidae & 169,794 & 179 & EU255577 & {$[29]$} \\
\hline Phthorimaea operculella granulovirus & Gelechiidae & 119,217 & 130 & AF499596 & $u / d$ \\
\hline Pieris rapae granulovirus China & Pieridae & 108,592 & 120 & GQ884143 & {$[30]$} \\
\hline Pieris rapae granulovirus E3 & Pieridae & 108,476 & 125 & GU111736 & $u / d$ \\
\hline Pieris rapae granulovirus South Korea & Pieridae & 108,658 & 120 & JX968491 & $u / d$ \\
\hline Plutella xylostella granulovirus & Plutellidae & 100,999 & 120 & AF270937 & {$[31]$} \\
\hline Pseudaletia unipuncta granulovirus & Noctuidae & 176,677 & 183 & EU678671 & $u / d$ \\
\hline Spodoptera litura granulovirus & Noctuidae & 124,121 & 136 & DQ288858 & [32] \\
\hline Xestia c-nigrum granulovirus & Noctuidae & 178,733 & 181 & AF162221 & [33] \\
\hline
\end{tabular}

$\mathrm{u} / \mathrm{d}$ - unpublished data.

were detected. However, we identified five putative homologous regions (hrs)/repeat regions lacking typical alphabaculovirus hr palindromes. This feature is also found in both Choristoneura occidentalis granulovirus (ChocGV) and Pieris rapae granulovirus (PiraGV) genomes. As observed in ChocGV [21], ErelGV lacks both gp37 and exon0, which was previously predicted for being shared among all Alpha and Betabaculovirus [22].

\section{Phylogenetic analysis}

In order to better understand the evolutionary history of ErelGV and the genus Betabaculovirus, we carried out a maximum likelihood phylogenetic analysis using the 37 baculovirus core gene alignment from all baculovirus genome available. ErelGV clustered with ChocGV and both viruses share the same ancestor with PiraGV isolates (Figure 2). Since the Chinese and Korean PiraGV isolates are very similar to each other (99.5\%), we have included only the Chinese isolate in our analyses. Using Mauve alignment [34], we found that ChocGV and PiraGV genomes have respectively $38.5 \%$ and $34.5 \%$ of global pairwise identity when compared to ErelGV genome. Additionally, our phylogenetic analyses did not find support for Betabaculovirus division in two clades (A and B), as described previously using neighbor joining clustering method $[25,28]$. Phylogenetic relationships in Baculoviridae, in particular in the genus Betabaculovirus, are difficult to discern due to the limited number of sequenced genomes available
(Table 1). Therefore, we further evaluated ErelGV phylogenetic relationships using granulin, lef-8, and lef-9 partial gene dataset as previously carried out [20,35] (28 partial sequences), but including new sequences publicly available (seven sequences from completely sequenced baculovirus) totalizing 35 granulovirus sequences. This analysis revealed that ErelGV isolate Br-S86 is closely related to another ErelGV (also called EeGV) from the Steinhaus collection [20] and that both are closer to Andraca bipunctata granulovirus (AnbiGV) (data not shown).

\section{Betabaculovirus gene comparison}

We performed BLAST comparisons between ErelGV and all other full betabaculovirus genomes available in Genbank using the CGView Comparison Tool [36] and CIRCOS [37]. As shown in Figure 3, most of the ErelGV-encoded ORFs are conserved among all betabaculovirus, but protein similarity varies widely across the species. Some structural proteins, such as granulin and the per os infectivity factors (PIFs), were the most conserved genes. Conversely, $\mathrm{F}$ protein, the major Betabaculovirus envelope fusion protein (EFP, encoded by ErelOrf-28) and matrix metalloproteinase (MMP, a stromelysin-1-like protein, encoded by ErelOrf-39) were particularly variable despite of both being present in every betabaculovirus sequenced to date. The EFP is essential for cell-to-cell movement and systemic virus spread [7]. GP64 is the EFP found in Group I Alphabaculovirus and all orthologs are closely related to 


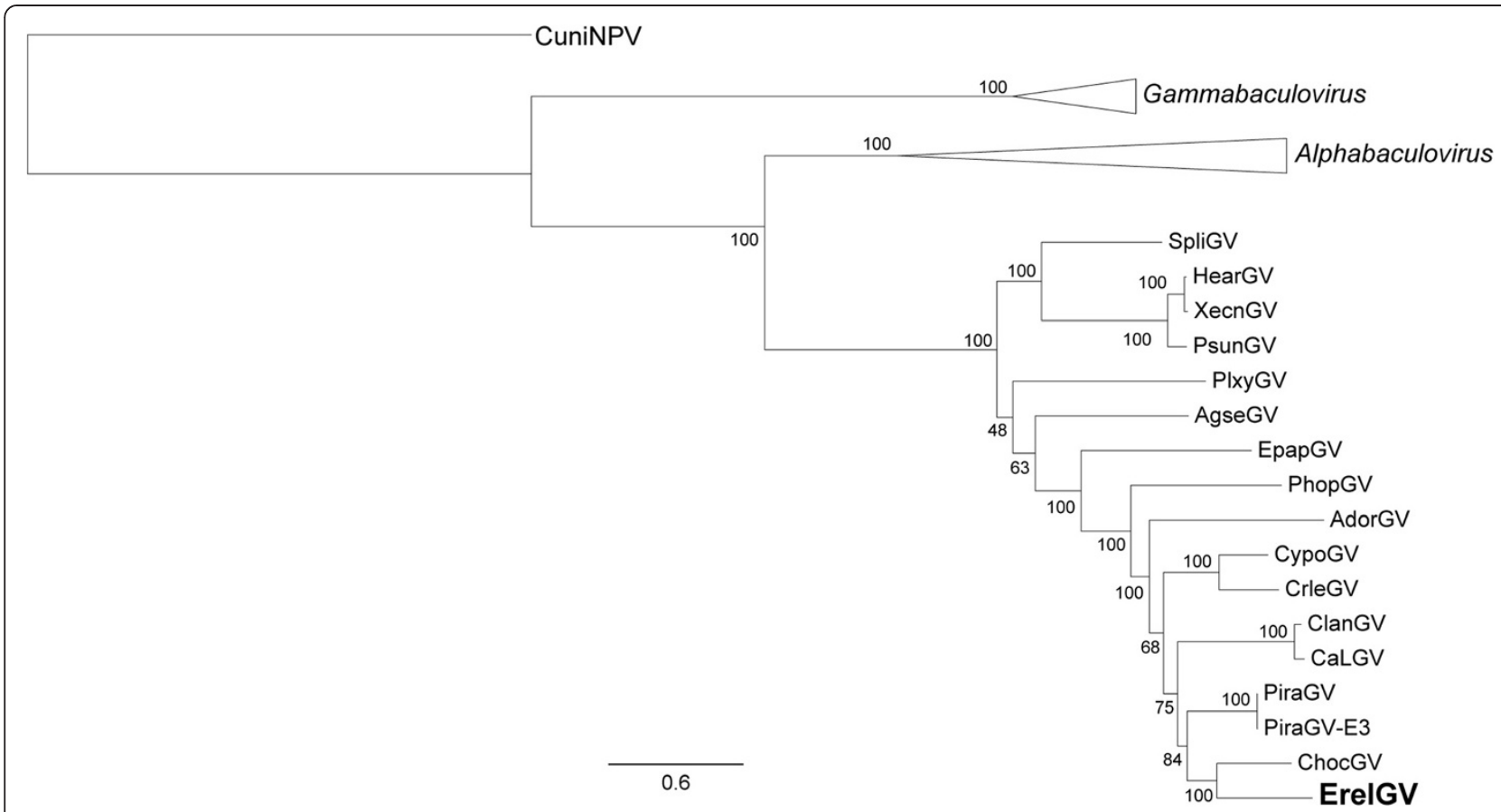

Figure 2 Maximum likelihood tree for Betabaculovirus. The phylogenetic inference was based on the concatenated amino acid sequences of the 37 core genes identified in all complete baculovirus genome sequences. We collapsed all the Gammabaculovirus and Alphaphabaculovirus. The CuniNPV was used as root. ErelGV (boldface) clustered with ChocGV and both were closely related to PiraGV isolates.

each other (81\% of protein sequence identity), whereas the F protein, found in both Alpha and Betabaculovirus [38], is very diverse (20 to $40 \%$ sequence identity). Interestingly, deletion of the gp64 or $f$ protein genes is lethal for BV propagation in Autographa californica multiple nucleopolyhedrovirus (AcMNPV) [39] and Helicoverpa armigera nuclepolyhedrovirus (HaNPV) [40,41], respectively. The deficiency can be rescued by efp homologs from many different viruses in the case of AcMNPV [42], but the opposite is not true; AcMNPV gp64 is not able to completely rescue an efp-deleted HaNPV. However, it is not clear why the F protein from Plutella xylostella granulovirus (PlxyGV) is not able to rescue the infectivity of gp64-null AcMNPV [42] but that from AgseGV can. PlxyGV causes systemic infection to the diamondback moth P. xylostella (Plutellidae) larvae [43] and AgseGV infects the cutworm A. segetum (Noctuidae) [44]. Thus, the betabaculovirus EFP variability might reflect the cell machinery adjustment at the insect family level considering that AcMNPV infects caterpillar from the same insect family of A. segetum. A second highly variable gene, MMP, is a proteinase able to produce a distinct pattern of melanization in Bombyx mori larvae infected with the Xestia c-nigrum granulovirus (XecnGV) metalloproteinaseexpressing Bombyx mori nucleopolyhedrovirus [45]. The enzyme is thought to enhance, replace, or act synergistically with proteins from virus or host playing an important role in the virus spread [46]. This variability is not unexpected since granulovirus genomes vary in content with respect to the presence or absence of the proteases cathepsin and enhancin genes and also the chitinase gene [12,45-47].

\section{Lack of cathepsin and chitinase genes}

ErelGV lacks cathepsin and chitinase genes, despite of their importance for promoting baculovirus horizontal transmission [48]. This feature can explain the integrity of caterpillar flesh and light color after death (Figure 1A). Other betabaculovirus genomes also lack both enzymes: complete deletion in ChocGV [21], Adoxophyes orana granulovirus (AdorGV) [23], Phthorimaea opercullela granulovirus (PhopGV) (unpublished), PlxyGV [31] and Spodoptera litura granulovirus (SpliGV) [32]; Cryptophlebia leucotreta granulovirus (CrleGV) [26] chitinase has an interruption; and in Helicoverpa armigera granulovirus (HearGV) [29] only cathepsin is absent. Interestingly, most of these deletions seem to have occurred independently of each other within Betabaculovirus (data not shown), aside from ChocGV and ErelGV in which is strongly supported an ancestral lacking. Thus, it is reasonable to expect that AnbiGV, the closest relative to ErelGV, might also lack both cathepsin and chitinase. Taken together, these results reinforce the notion that both genes are most likely non-essential for the persistence of baculoviruses in the environment. Conversely, previous work from our research team has shown that introduction of cathepsin and chitinase from Choristoneura fumiferana defective 


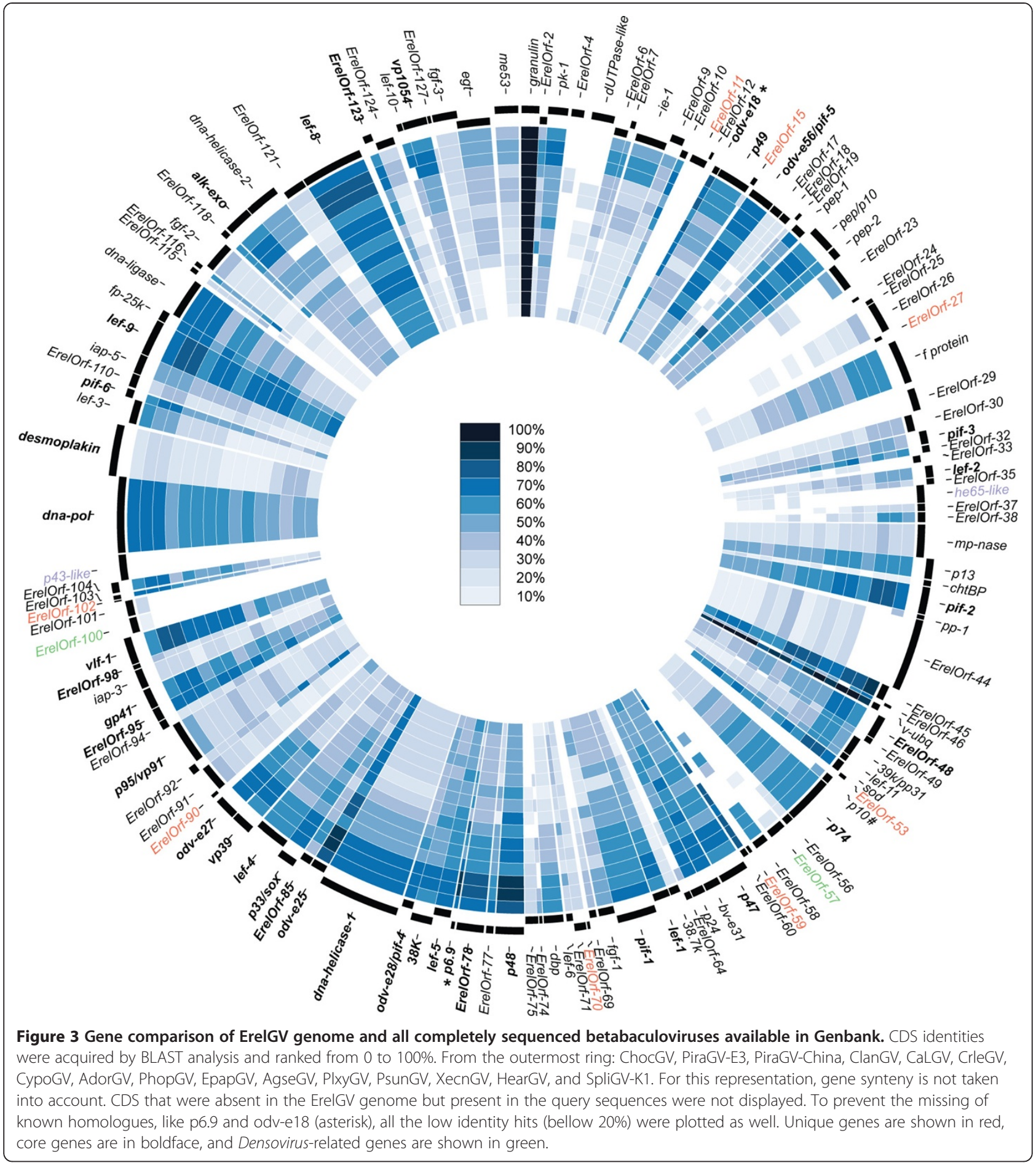

nucleopolyhedrovirus into AgMNPV (which naturally lacks both genes) increases pathogenicity and occlusion body production relative to the wild type virus [49].

\section{dUTPase-like gene}

ErelOrf-5 codes for a nucleotide metabolism-related gene homologous to Orgyia pseudotsugata multiple nucleopolyhedrovirus (OpMNPV) Orf-31. The gene seems to be composed of a fusion between two distinct ORFs; the C-terminal portion is related to a baculovirus thymidylate kinase-like gene and the $\mathrm{N}$-terminal portion is related to several $d U T P a s e-l i k e$ genes. The thymidylate kinase enzyme catalyzes a critical step in the biosynthesis of deoxythymidine triphosphate [50]. dUTPase catalyses 
dUTP dephosphorylation to generate dUMP [51]. High levels of dUTP can be deleterious for virus genomic DNA replication since dTTP can be substituted for dUTP during DNA synthesis [52]. A high dUTP/dTTP ratio promotes uracil incorporation into DNA. Uracils in DNA are then targeted by uracil DNA glycosylase and excised, leading to futile repair cycles and DNA breakage and or translesional DNA synthesis [53,54]. Nucleotide metabolism-related enzyme acquisition is common in baculoviruses [28] and could avoid this deleterious response by decreasing the dUTP/dTTP ratio, however how these genes alter the virus fitness is not clear [55].

\section{The he65-like and $p 43$-like genes}

The ErelGV genome contains homologues of the he65 and $p 43$ genes. Homologues of he65 are harbored by several alphabaculoviruses, four betabaculoviruses (Agrotis segetum granulovirus (AgseGV), HearGV, Pseudaletia unipuncta granulovirus (PsunGV), and Xestia c-nigrum granulovirus (XecnGV)), and two betaentomopoxviruses (Amsacta moorei entomopoxvirus - AMV and Mythimna separate entomopoxvirus - MSV). This gene is a member of a distinct RNA ligase family related to the T4 RNA ligase gp63like gene and is present in all the domains of life (Bacteria, Archaea, and Eukarya) [7,56]. The alignment of baculovirus and entomopoxvirus he65-like genes revealed large, independent, and recurrent deletions in the C-terminal region (data not shown), which contain five nucleotidyl transferase motifs [56]. The amino-terminal region was highly conserved although no previously characterized motifs were present. We performed a phylogenetic reconstruction based on this conserved domain. The he65 reconstruction revealed distinct horizontal gene transfer (HGT) events from Alphabaculovirus to Betabaculovirus and Betaentomopoxvirus (Figure 4A). Betabaculovirus likely endured two independent acquisitions from Group II Alphabaculovirus in distinct genomic regions: (i) a synapomorphic introduction for HearGV, PsunGV, and XecnGV (Figure 4A, orange rectangle); and (ii) an additional gain for AgseGV (Figure 4A, dark orange rectangle). Importantly, support for AgseGV branch is low. However, the genomic context of the gene is conserved among HearGV, PsunGV, and XecnGV but not in AgseGV (data not shown), reinforcing our hypothesis that two independent introductions occurred. Likewise, Betaentomopoxvirus homologues were probably acquired from Group II Alphabaculovirus (Figure 4, yellow rectangle). Remarkably, ErelGV is the first Betabaculovirus with a he65-like gene (ErelOrf-36 - Figure 4A, green rectangle) acquired from Group I Alphabaculovirus. It is not clear whether C-terminal deleted he65 remains functional in baculovirus. However the maintenance of the amino-terminal region indicates that this gene region is under positive selection pressure.
Furthermore, we found in ErelGV genome a p43-like gene (ErelOrf-105) whose homologues were found only in baculovirus species from the genus Alphabaculovirus (Figure 4B) with conserved amino acid sequence and position in the genome [7]. Deletion of $p 43$ in AcMNPV does not affect virus replication in cell culture and the reason for gene acquisition and preservation is not clear [57]. Two hypotheses can be raised for $p 43$ introduction in ErelGV: $(i)$ ErelGV acquired the $p 43$-like gene from Group I Alphabaculovirus, specifically from AcMNPVrelated viruses; or (ii) ErelGV acquired from Group II Alphabaculovirus, specifically from a baculovirus (e.g. Clanis bilineata nucleopolyhedrovirus - ClbiNPV [58]) during co-infection of a sphingid host.

\section{Acquisitions of Densovirus-related genes in Betabaculovirus}

ErelOrf-57 and ErelOrf-100 are homologues to a nonstructural Densovirus gene. Densovirus-related genes were previously described in two betabaculoviruses, ChocGV (ChocOrf-25) [21] and CrleGV (CrleOrf-9) [26], and one gammabaculovirus (baculovirus infective to hymenoptera), Neodiprion lecontei nucleopolyhedrovirus (NeleNPV NeleOrf-81) [59]. The latter did not match the other two homologues (data not shown), suggesting these genes resulted from at least two HGT events between densoviruses and baculoviruses. Despite the limited number of Densovirus genomes available, we performed a phylogenetic analysis to help understand the origins of Betabaculovirus homologues. We found that the genes were dispersed over the phylogenetic tree, suggestive of multiple HGT events. As shown in Figure 5, Betabaculovirus homologues did not form a monophyletic cluster. To further substantiate our findings, we compared the likelihood of the observed tree to that estimated assuming a Betabaculovirus monophyletic clade (single-HGT event). Indeed, the likelihood ratio test rejected the monophyletic hypothesis favoring the multipleHGT scenario, which was also supported by the distinct genomic context observed for the homologous betabaculovirus genes (data not shown). Moreover, both ErelOrf-57 and ErelOrf-100 form a well-supported clade, indicating that they probably represent a gene duplication event during ErelGV evolution.

\section{Conclusion}

ErelGV is a new betabaculovirus species closely related to ChocGV and PiraGV isolates. Its genome encodes 130 ORFs, eight of which are unique. We found evidence suggesting horizontal gene transfers from Alphabaculovirus and Densovirus to Betabaculovirus. The he65-like gene was independently acquired tree times from Alphabaculovirus. We found a dUTPase-like gene homologous to OpMNPV Orf-31 and two Densovirus-related genes. The contribution of these genes to baculovirus fitness is not clear and is 


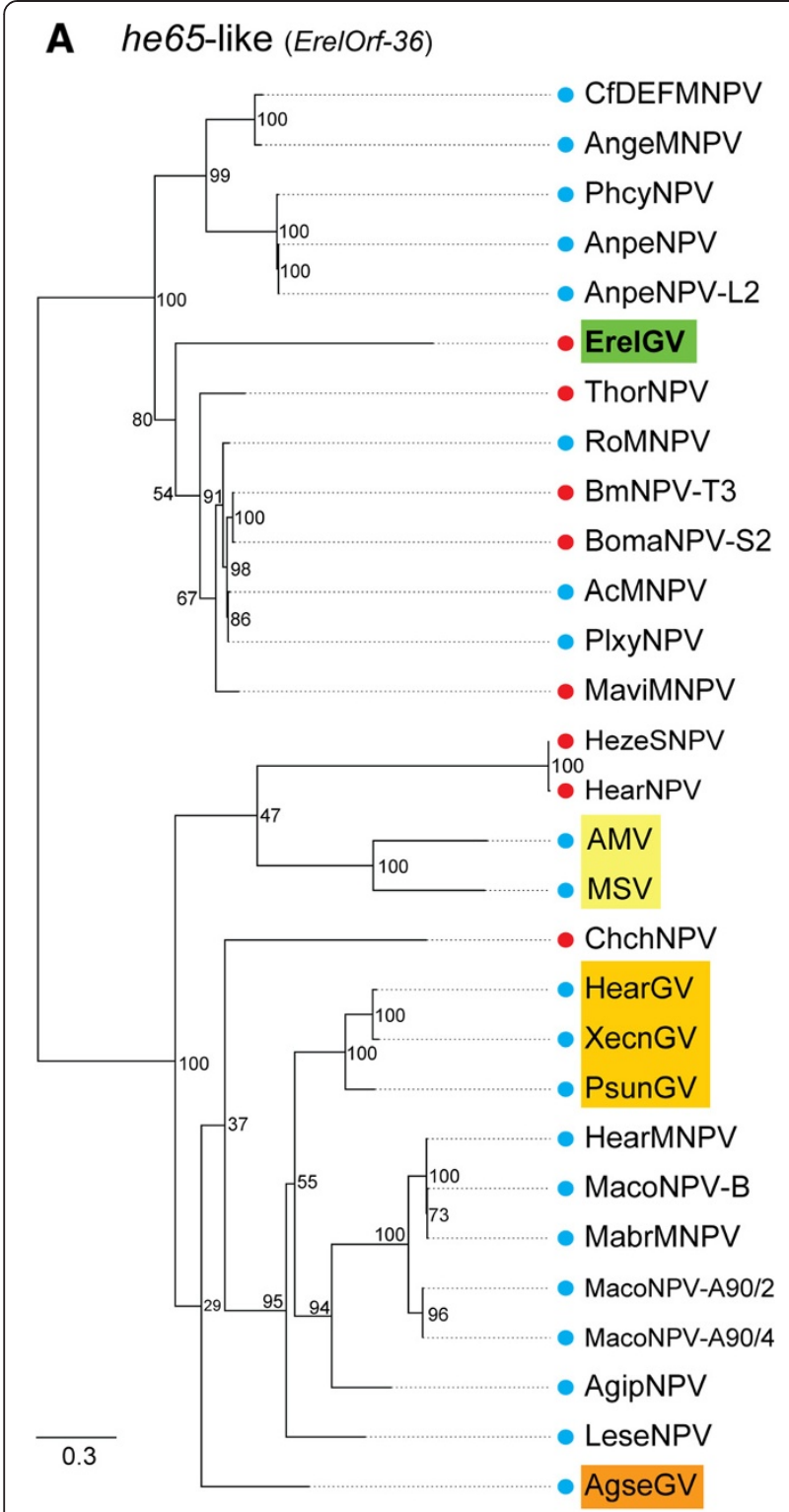

B p43-like (ErelOrf-105)

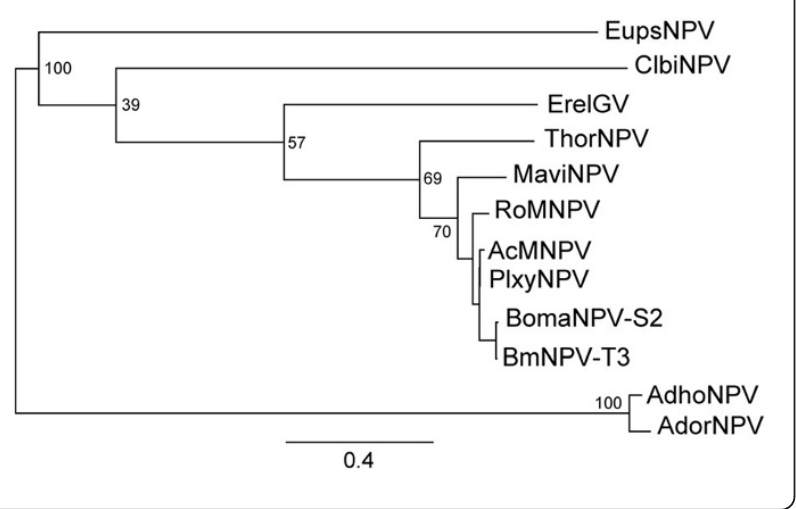

Figure 4 Phylogeny of he65 and p43 reveals horizontal gene transfer in ErelGV from Alphabaculovirus. (A) The maximum likelihood (ML) tree was inferred using the conserved amino-terminal region alignment of he65-like gene for 36 baculoviruses and two entomopoxviruses. Circles indicate the presence (blue) or absence (red) of the carboxy-terminal region. The postulated horizontal gene transfer (HGT) events are highlighted for Betabaculovirus (light and dark orange), Betaentomopoxvirus (yellow), and ErelGV (green). (B) ML-Phylogenetic reconstruction for $p 43$-like gene found in ErelGV genome. The trees are midpoint rooted for purposes of clarity.

being experimentally tested in our lab. Importantly, recombination events between insect viruses from unrelated families and genera might drive baculovirus genomic evolution.

\section{Nucleotide sequence accession number}

The ErelGV genome sequence was submitted to GenBank under accession number KJ406702.

\section{Availability of supporting data}

The complete ErelGV genome sequence has been submitted to GenBank (accession number KJ406702). All supporting data is included as additional files.

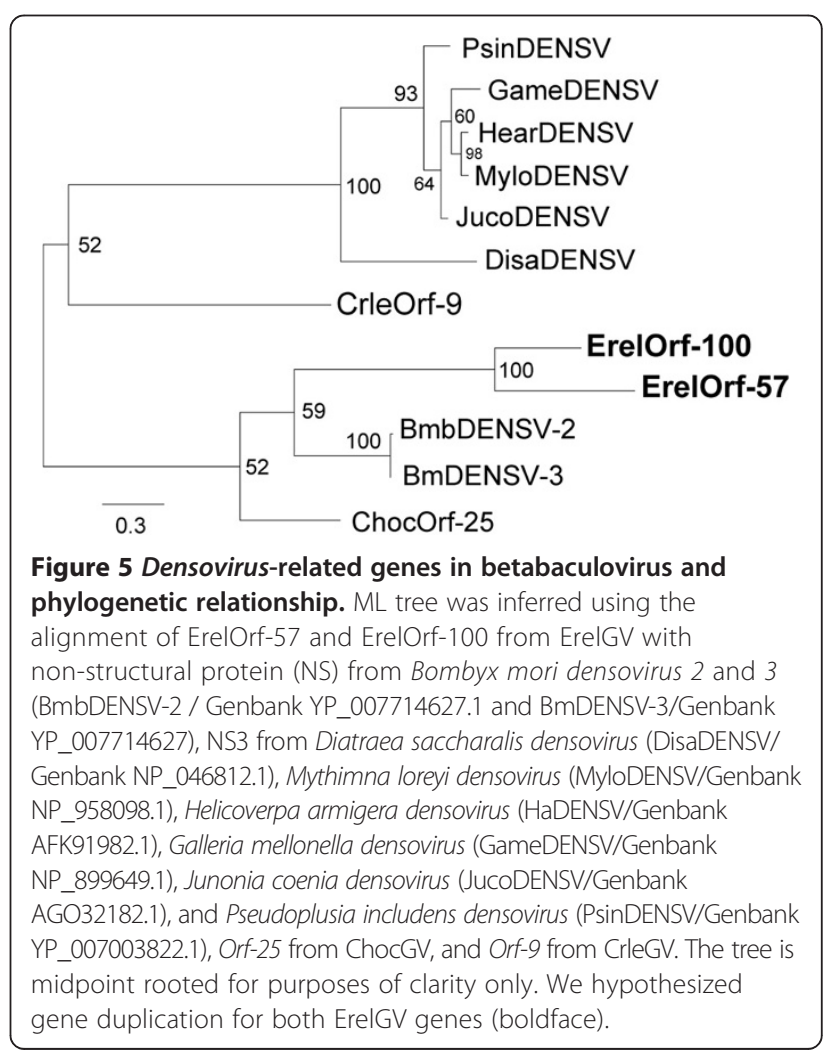




\section{Methods}

\section{Virus purification}

Insect cadavers of the hornworm E. ello ello with baculovirus infection symptoms were collected in cassava crops in the South of Brazil (Itajaí, Santa Catarina) in 1986. They were kindly provided by Dr. Renato Arcanjo Pegoraro (EPAGRI). The cadavers were kept in the freezer and later used for OBs purification. Insect cadavers were homogenized with $\mathrm{ddH}_{2} \mathrm{O}(\mathrm{w} / \mathrm{v})$, filtered through three layers of gauze, and centrifuged at 7,000 $x \mathrm{~g}$ for $10 \mathrm{~min}$. The pellet was resuspended in $0.5 \%(\mathrm{w} / \mathrm{v})$ SDS and again centrifuged at 7,000 $x \mathrm{~g}$ for $10 \mathrm{~min}$. The dilution and centrifugation steps were repeated four times, and the final pellet was washed in $0.5 \mathrm{M} \mathrm{NaCl}$. The pellet was resuspended in $\mathrm{ddH}_{2} \mathrm{O}$, loaded onto a continuous $40-65 \%$ sucrose gradient, and centrifuged at $104.000 \times g$ for $40 \mathrm{~min}$ at $4^{\circ} \mathrm{C}$. The $\mathrm{OB}$ band was collected, diluted 4-fold in $\mathrm{dd}_{2} \mathrm{O}$, and centrifuged at 7,000 $\times g$ for $15 \mathrm{~min}$ at $4{ }^{\circ} \mathrm{C}$.

\section{Electron microscopy}

For scanning electron microscopy (SEM), $100 \mu \mathrm{l}$ of the OB-containing solution $\left(10^{9} \mathrm{OBs} / \mathrm{ml}\right)$ were incubated with $300 \mu \mathrm{l}$ of acetone at $25^{\circ} \mathrm{C}$ for 1 hour. The solution was loaded in a metallic stub, dried overnight at $37^{\circ} \mathrm{C}$, coated with gold in a Sputter Coater (Balzers) for $3 \mathrm{~min}$, and observed in a scanning electron microscope Jeol JSM 840 A at $10 \mathrm{kV}$. For transmission electron microscopy (TEM) pellets of purified granules were fixed in Karnovsky fixative $(2.5 \%$ glutaraldehyde, $2 \%$ paraformaldehyde, in $0.1 \mathrm{M}$, cacodylate buffer, $\mathrm{pH} 7.2$ ) for $2 \mathrm{~h}$, post-fixed in $1 \%$ osmium tetroxide in the same buffer for $1 \mathrm{~h}$ and then stained en bloc with $0.5 \%$ aqueous uranyl acetate, dehydrated in acetone, and embedded in Spurr's low viscosity embedding medium. The ultrathin sections were contrasted with $2 \%$ uranyl acetate and observed in a ZEISS TEM 109 at $80 \mathrm{kV}$.

\section{Genomic DNA restriction analyses}

Purified granules $\left(10^{9} \mathrm{OBs} / \mathrm{ml}\right)$ were dissolved in an alkaline solution and used to extract DNA according to O'Reilly et al. [60]. The quantity and quality of the isolated DNA were determined by electrophoresis on $0.8 \%$ agarose (data not shown). The viral DNA (1-2 $\mu \mathrm{g})$ was individually cleaved with the restriction enzymes HindIII, EcoRI, and BamHI (Promega) according to manufacturer's instructions. The DNA fragments generated were analyzed by $0.8 \%$ agarose gel electrophoresis [61], visualized, and photographed in AlphaImager Mini (Alpha Innothech).

\section{Genome sequencing, assembly, and annotation}

ErelGV genomic DNA was sequenced with the 454 Genome Sequencer (GS) FLX $X^{\text {ma }}$ Standard (Roche) at the Centro de Genômica de Alto Desempenho do Distrito Federal (Brasília, Brazil). The genome was assembled de novo using Geneious 6.0 [62] and confirmed using restriction enzyme digestion profile. The annotation was performed using Geneious 6.0 to identify the open reading frames (ORFs) that started with a methionine codon (ATG) encoding at least 50 amino acids and blastp [63] to identify homologues.

\section{Phylogeny, genome, and gene comparisons}

For Baculoviridae phylogenetic analysis, a MAFFT alignment [64] was carried out with concatenated amino acid sequences predicted for 37 baculovirus core genes. A maximum likelihood tree was inferred using PhyML with 100 repetitions of a non parametric bootstrap [65], implemented in Geneious, with $\mathrm{LG}+\mathrm{I}+\mathrm{G}+\mathrm{F}$ model selected by Prottest 2.4 [66]. Moreover, a genomic comparison was performed using the protein dataset of all the complete Betabaculovirus genomes available in Genbank. The dataset was compared using CGView Comparison Tool [36] and the results were plotted using CIRCOS [37]. We also compared ChocGV and PiraGV genomes with ErelGV genome using Mauve alignment [34]. The horizontal gene transfer (HGTs) events were investigated comparing the maximum likelihood phylogenetic tree inferred using the RAxML method [67] and a MAFT alignment of homologues for he65-like and p43-like, and Densovirus-related genes with 100 repetitions of a non parametric bootstrap for branch support.

\section{Additional file}

\section{Additional file 1: Table S1. Characteristics of the Erinnyis ello} granulovirus (ErelGV) genome: analysis and homology search. Predicted ORFs are compared with homologous genes in three related genomes.

\section{Competing interests}

The authors declare that they have no competing interests.

\section{Author's contributions}

Conceived and designed the experiments: DMPAA, FLM, BMR, MLS; Performed the experiments: DMPAA, FLM, MSA, WS; Analyzed the data: DMPAA, FLM, BMR; Contributed reagents/materials/analysis tools: BMR, DMPAA, FLM, MSA, SNB, MLS; Wrote the paper: DMPAA, FLM, BMR, MLS. All authors read and approved the final manuscript.

\section{Acknowledgements}

We thank Conselho Nacional de Desenvolvimento Científico e Tecnológico (CNPq), Fundação de Apoio à Pesquisa do Distrito Federal (FAPDF), Coordenação de Aperfeiçoamento de Pessoal de Nível Superior (CAPES), and EMBRAPA Recursos Genéticos e Biotecnologia for the financial support; José Osmar Lorenzi for the picture of E. ello ello infected by ErelGV; Ingrid Gracielle Martins da Silva for kindly helping with the sample for microscopy; and Jeffrey J. Hodgson for kindly reviewing the English writing style.

\section{Author details}

${ }^{1}$ Cell Biology Department, Laboratory of Baculovirus, University of Brasília, 70910-900 Brasília, DF, Brazil. Embrapa Genetic Resources and Biotechnology, Biological Station Park, 70770-917 Brasília, DF, Brazil.

Received: 1 March 2014 Accepted: 25 September 2014

Published: 4 October 2014 


\section{References}

1. El-Sharkawy MA: Cassava biology and physiology. Plant Mol Biol 2004, 56(4):21.

2. Pietrowski V, Ringenberger R, Rheinheimer AR, Bellon PP, Gazola D, Miranda AM: Insetos-praga da cultura da mandioca na região Centro-Sul do Brasil. Volume 1. Marechal Cândido Rondon - Parana: EMBRAPA; 2010.

3. Bellotti AC, Arias B, Guzman OL: Biological control of the cassava hornworm erinnyis ello (Lepidoptera: Sphingidae). The Florida Entomologist 1992, 75(4):10.

4. Fazolin M, Estrela JLV, Filho MDC, Santiago ACC, Frota FS: Manejo Integrado do Mandarová-da-Mandioca Erinnyis ello (L.) (Lepidoptera: Sphingidae): Conceitos e Experiências na Região do Vale do Rio Juruá, Acre. Edited by Embrapa. Rio Branco, Brasil: Embrapa; 2007.

5. Schmitt AT: Eficiência da aplicação de Baculovirus erinnyis no controle do mandarová da mandioca. Volume 88. Florianópolis, Santa Catarina Brasil: EMPASC Comunicado Técnico edn; 1985.

6. Schmitt AT: Principais insetos pragas da mandioca e seu controle. In Cultura de tuberosas amiláceas Latino Americanas, Volume 2. Edited by Cereda MP. São Paulo: Fundação Cargill; 2002:7.

7. Rohrmann GF: Baculovirus Molecular Biology, Third Edition [Internet] edn Bethesda (MD): National Center for Biotechnology Information (US). Available from: http:/www.ncbi.nlm.nih.gov/books/NBK49500/; 2011

8. Jehle JA, Blissard GW, Bonning BC, Cory JS, Herniou EA, Rohrmann GF, Theilmann DA, Thiem SM, Vlak JM: On the classification and nomenclature of baculoviruses: a proposal for revision. Arch Virol 2006, 151(7):1257-1266.

9. Herniou EA, Arif BM, Becnel JJ, Blissard GW, Bonning B, Harrison R, Jehle JA, Theilmann DA, Vlak JM: Baculoviridae. In Virus taxonomy Ninth Report of the International Committee on Taxonomy of Viruses. Edited by King AMQ, Adams MJ, Carstens EB, Lefkowitz EJ. San Diego: Elsevier-Academic Press; 2012:163-173.

10. Moscardi F: Assessment of the application of baculoviruses for control of Lepidoptera. Annu Rev Entomol 1999, 44:257-289.

11. Ji X, Sutton G, Evans G, Axford D, Owen R, Stuart DI: How baculovirus polyhedra fit square pegs into round holes to robustly package viruses. EMBO J 2010, 29(2):505-514.

12. Slack J, Arif BM: The baculoviruses occlusion-derived virus: virion structure and function. Adv Virus Res 2007, 69:99-165.

13. Wang R, Deng F, Hou D, Zhao Y, Guo L, Wang H, Hu Z: Proteomics of the Autographa californica nucleopolyhedrovirus budded virions. J Virol 2010, 84(14):7233-7242.

14. Washburn JO, Chan EY, Volkman LE, Aumiller JJ, Jarvis DL: Early synthesis of budded virus envelope fusion protein GP64 enhances Autographa californica multicapsid nucleopolyhedrovirus virulence in orally infected Heliothis virescens. J Virol 2003, 77(1):280-290.

15. Herniou EA, Olszewski JA, Cory JS, O'Reilly DR: The genome sequence and evolution of baculoviruses. Annu Rev Entomol 2003, 48:211-234.

16. Herniou EA, Luque T, Chen X, Vlak JM, Winstanley D, Cory JS, O'Reilly DR: Use of whole genome sequence data to infer baculovirus phylogeny. J Virol 2001, 75(17):8117-8126.

17. Hoover K, Grove M, Gardner M, Hughes DP, McNeil J, Slavicek J: A gene for an extended phenotype. Science 2011, 333(6048):1401.

18. Ackermann H, Smirnoff W: A morphological investigation of 23 baculoviruses. J Invertebr Pathol 1983, 41:12

19. Finnerty CM, Li G, Granados RR: Characterization of a granulovirus from the cassava hornworm (Erinnyis ello: Sphingidae). I Invertebr Pathol 2000, 75(4):273-278

20. Jehle JA, Lange M, Wang H, Hu Z, Wang Y, Hauschild R: Molecular identification and phylogenetic analysis of baculoviruses from Lepidoptera. Virology 2006, 346(1):180-193.

21. Escasa SR, Lauzon HA, Mathur AC, Krell PJ, Arif BM: Sequence analysis of the Choristoneura occidentalis granulovirus genome. J Gen Virol 2006, 87(Pt 7):1917-1933.

22. Garavaglia MJ, Miele SA, Iserte JA, Belaich MN, Ghiringhelli PD: The ac53, ac78, ac101, and ac103 genes are newly discovered core genes in the family Baculoviridae. J Virol 2012, 86(22):12069-12079.

23. Wormleaton S, Kuzio J, Winstanley D: The complete sequence of the Adoxophyes orana granulovirus genome. Virology 2003, 311(2):350-365.

24. Zhang $X$, Liang Z, Yin X, Wang J, Shao X: Complete genome sequence of Agrotis segetum granulovirus Shanghai strain. Arch Virol 2014. http://dx. doi.org/10.1007/s00705-014-2001-y.

25. Liang Z, Zhang X, Yin X, Cao S, Xu F: Genomic sequencing and analysis of Clostera anachoreta granulovirus. Arch Virol 2011, 156(7):1185-1198.
26. Lange $M$, Jehle JA: The genome of the Cryptophlebia leucotreta granulovirus. Virology 2003, 317(2):220-236.

27. Luque T, Finch R, Crook N, O'Reilly DR, Winstanley D: The complete sequence of the Cydia pomonella granulovirus genome. J Gen Virol 2001, 82(Pt 10):2531-2547

28. Ferrelli ML, Salvador R, Biedma ME, Berretta MF, Haase S, Sciocco-Cap A, Ghiringhelli PD, Romanowski V: Genome of Epinotia aporema granulovirus (EpapGV), a polyorganotropic fast killing betabaculovirus with a novel thymidylate kinase gene. BMC Genomics 2012, 13:14.

29. Harrison RL, Popham HJ: Genomic sequence analysis of a granulovirus isolated from the Old World bollworm, Helicoverpa armigera. Virus Genes 2008, 36(3):565-581.

30. Zhang BQ, Cheng RL, Wang XF, Zhang CX: The Genome of Pieris rapae Granulovirus. J Virol 2012, 86(17):9544.

31. Hashimoto Y, Hayakawa T, Ueno Y, Fujita T, Sano Y, Matsumoto T: Sequence analysis of the Plutella xylostella granulovirus genome. Virology 2000, 275(2):358-372.

32. Wang Y, Choi JY, Roh JY, Liu Q, Tao XY, Park JB, Kim JS, Je YH: Genomic sequence analysis of granulovirus isolated from the tobacco cutworm, Spodoptera litura. PLoS One 2011, 6(11):e28163.

33. Hayakawa T, Ko R, Okano K, Seong SI, Goto C, Maeda S: Sequence analysis of the Xestia c-nigrum granulovirus genome. Virology 1999, 262(2):277-297.

34. Darling AC, Mau B, Blattner FR, Perna NT: Mauve: multiple alignment of conserved genomic sequence with rearrangements. Genome Res 2004, 14(7):1394-1403.

35. Lange $M$, Wang $H$, Zhihong $H$, Jehle JA: Towards a molecular identification and classification system of lepidopteran-specific baculoviruses. Virology 2004, 325(1):36-47.

36. Grant JR, Arantes AS, Stothard P: Comparing thousands of circular genomes using the CGView Comparison Tool. BMC Genomics 2012, 13:8.

37. Krzywinski M, Schein J, Birol I, Connors J, Gascoyne R, Horsman D, Jones SJ, Marra MA: Circos: an information aesthetic for comparative genomics. Genome Res 2009, 19(9):1639-1645.

38. Pearson MN, Rohrmann GF: Transfer, incorporation, and substitution of envelope fusion proteins among members of the Baculoviridae Orthomyxoviridae, and Metaviridae (insect retrovirus) families. J Virol 2002, 76(11):5301-5304.

39. Oomens AG, Blissard GW: Requirement for GP64 to drive efficient budding of Autographa californica multicapsid nucleopolyhedrovirus. Virology 1999, 254(2):297-314

40. Wang M, Yin F, Shen S, Tan Y, Deng F, Vlak JM, Hu Z, Wang H: Partial functional rescue of Helicoverpa armigera single nucleocapsid nucleopolyhedrovirus infectivity by replacement of F protein with GP64 from Autographa californica multicapsid nucleopolyhedrovirus. J Virol 2010, 84(21):11505-11514.

41. Wang M, Tan Y, Yin F, Deng F, Vlak JM, Hu Z, Wang H: The F protein of Helicoverpa armigera single nucleopolyhedrovirus can be substituted functionally with its homologue from Spodoptera exigua multiple nucleopolyhedrovirus. J Gen Virol 2008, 89(Pt 3):791-798.

42. Lung O, Westenberg M, Vlak JM, Zuidema D, Blissard GW: Pseudotyping Autographa californica multicapsid nucleopolyhedrovirus (AcMNPV): $F$ proteins from group II NPVs are functionally analogous to AcMNPV GP64. J Virol 2002, 76(11):5729-5736.

43. Harrison RL, Lynn DE: Genomic sequence analysis of a nucleopolyhedrovirus isolated from the diamondback moth, Plutella xylostella. Virus Genes 2007, 35(3):857-873.

44. Wennmann JT, Jehle JA: Detection and quantitation of Agrotis baculoviruses in mixed infections. J Virol Methods 2014, 197:39-46.

45. Ko R, Okano K, Maeda S: Structural and functional analysis of the Xestia c-nigrum granulovirus matrix metalloproteinase. J Virol 2000, 74(23):11240-11246

46. Means JC, Passarelli AL: Viral fibroblast growth factor, matrix metalloproteases, and caspases are associated with enhancing systemic infection by baculoviruses. Proc Natl Acad Sci U S A 2010, 107(21):9825-9830.

47. Lepore LS, Roelvink PR, Granados RR: Enhancin, the granulosis virus protein that facilitates nucleopolyhedrovirus (NPV) infections, is a metalloprotease. J Invertebr Pathol 1996, 68(2):131-140.

48. D'Amico V, Slavicek J, Podgwaite JD, Webb R, Fuester R, Peiffer RA: Deletion of $\mathrm{v}$-chiA from a baculovirus reduces horizontal transmission in the field. Appl Environ Microbiol 2013, 79(13):4056-4064 
49. Lima AA, Aragao CW, de Castro ME, Oliveira JV, Sosa Gomez DR, Ribeiro BM: A Recombinant MNPV Harboring and Genes from Defective NPV Induce Host Liquefaction and Increased Insecticidal Activity. PLoS One 2013, 8(9):e74592.

50. Cui Q, Shin WS, Luo Y, Tian J, Cui H, Yin D: Thymidylate kinase: an old topic brings new perspectives. Curr Med Chem 2013, 20(10):1286-1305.

51. Penades JR, Donderis J, Garcia-Caballer M, Tormo-Mas MA, Marina A: dUTPases, the unexplored family of signalling molecules. Curr Opin Microbiol 2013, 16(2):163-170.

52. Priet S, Sire J, Querat G: Uracils as a cellular weapon against viruses and mechanisms of viral escape. Curr HIV Res 2006, 4(1):31-42.

53. Castillo-Acosta VM, Aguilar-Pereyra F, Bart JM, Navarro M, Ruiz-Perez LM, Vidal AE, Gonzalez-Pacanowska D: Increased uracil insertion in DNA is cytotoxic and increases the frequency of mutation, double strand break formation and VSG switching in Trypanosoma brucei. DNA Repair (Amst) 2012, 11(12):986-995.

54. Guillet M, Van Der Kemp PA, Boiteux S: dUTPase activity is critical to maintain genetic stability in Saccharomyces cerevisiae. Nucleic Acids Res 2006, 34(7):2056-2066.

55. Herniou EA, Jehle JA: Baculovirus phylogeny and evolution. Curr Drug Targets 2007, 8(10):1043-1050.

56. Ho CK, Shuman S: Bacteriophage T4 RNA ligase 2 (gp24.1) exemplifies a family of RNA ligases found in all phylogenetic domains. Proc Natl Acad Sci U S A 2002, 99(20):12709-12714.

57. Yu M, Carstens EB: Characterization of an Autographa californica multiple nucleopolyhedrovirus mutant lacking the ac39(p43) gene. Virus Res 2011, 155(1):300-306.

58. Zhu SY, Yi JP, Shen WD, Wang LQ, He HG, Wang Y, Li B, Wang WB: Genomic sequence, organization and characteristics of a new nucleopolyhedrovirus isolated from Clanis bilineata larva. BMC Genomics 2009, 10:91.

59. Lauzon HA, Lucarotti CJ, Krell PJ, Feng Q, Retnakaran A, Arif BM: Sequence and organization of the Neodiprion lecontei nucleopolyhedrovirus genome. J Virol 2004, 78(13):7023-7035.

60. O'Reilly D, Miller LK, Luckow VA: Baculovirus Expression Vectors: a laboratory manual. New York: Freeman and Company; 1992.

61. Sambrook J, Russel DW: Molecular Cloning: a laboratory manual, 3rd ed. edn. New York: Cold Spring Harbor; 2001.

62. Kearse M, Moir R, Wilson A, Stones-Havas S, Cheung M, Sturrock S, Buxton S, Cooper A, Markowitz S, Duran C, Thierer T, Ashton B, Meintjes P, Drummond A: Geneious Basic: an integrated and extendable desktop software platform for the organization and analysis of sequence data. Bioinformatics 2012, 28(12):1647-1649.

63. Altschul SF, Madden TL, Schaffer AA, Zhang J, Zhang Z, Miller W, Lipman DJ: Gapped BLAST and PSI-BLAST: a new generation of protein database search programs. Nucleic Acids Res 1997, 25(17):3389-3402.

64. Katoh K, Misawa K, Kuma K, Miyata T: MAFFT: a novel method for rapid multiple sequence alignment based on fast Fourier transform. Nucleic Acids Res 2002, 30(14):3059-3066.

65. Guindon S, Dufayard JF, Lefort V, Anisimova M, Hordijk W, Gascuel O: New algorithms and methods to estimate maximum-likelihood phylogenies: assessing the performance of PhyML 3.0. Syst Biol 2010, 59(3):307-321.

66. Abascal F, Zardoya R, Posada D: ProtTest: selection of best-fit models of protein evolution. Bioinformatics 2005, 21(9):2104-2105.

67. Stamatakis A, Hoover P, Rougemont J: A rapid bootstrap algorithm for the RAxML Web servers. Syst Biol 2008, 57(5):758-771.

doi:10.1186/1471-2164-15-856

Cite this article as: Ardisson-Araújo et al:: Genome sequence of Erinnyis ello granulovirus (ErelGV), a natural cassava hornworm pesticide and the first sequenced sphingid-infecting betabaculovirus. BMC Genomics 2014 15:856.

\section{Submit your next manuscript to BioMed Central and take full advantage of:}

- Convenient online submission

- Thorough peer review

- No space constraints or color figure charges

- Immediate publication on acceptance

- Inclusion in PubMed, CAS, Scopus and Google Scholar

- Research which is freely available for redistribution

Submit your manuscript at www.biomedcentral.com/submit 